\title{
Experimental investigation of multiphase separation in different flow regimes through T-junction with an expander section
}

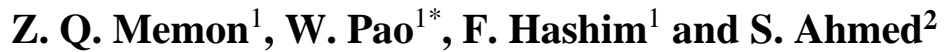 \\ ${ }^{1}$ Department of Mechanical Engineering, Universiti Teknologi PETRONAS, \\ 32610 Seri Iskandar, Perak, MALAYSIA, \\ ${ }^{2}$ Advanced Chemistry Lab, Sukkur IBA University, Airport Road Sukkur, \\ Sindh PAKISTAN, \\ *Email: william.pao@utp.edu.my
}

\begin{abstract}
T-junctions are employed as partial phase separator in the oil and gas industry. The present T-junctions are poorly designed and causing high liquid carry-over with gas phase resulting in malfunction of downstream equipment. This paper presents the novel T-junction design with expander section after the branch arm in order to improve the two-phase separation. The main and run arms of the T-junction are directed along the horizontal plane with the branch arm positioned in the vertical plane. The diameter of the main arm is $0.074 \mathrm{~m}$, with diameter ratio(s) of, 0.67 , and 0.33 in relation to branch arm. At the inlet section of the $\mathrm{T}$-junction, the flow regimes generated were stratified, stratified-wavy, and slug flow. At the inlet, the air and water superficial velocities are in the range of $0.25-0.140 \mathrm{~m} / \mathrm{s}$ and $0.14-0.78 \mathrm{~m} / \mathrm{s}$ respectively. The effect of the expander section after the branch arm, the air superficial velocity $U_{\mathrm{SA}}$ and water superficial velocity $U_{\mathrm{SW}}$ on liquid carry-over $\left(W_{\mathrm{L} 3} / W_{\mathrm{L} 1}\right)$ max in branch arm have been studied. Based on the experimental data obtained for T-junction with expander section, complete phase separation of air and water was observed in stratified and stratifiedwavy flow for all superficial velocities and improved phase separation for slug flow. In slug flow, increasing the liquid superficial velocity improves the phase separation but increasing the superficial gas velocity decreases the phase separation. Finally, phase separation results of new T-junction design is compared with the phase separation data of a simple T-junction. Keywords: Stratified; stratified-wavy; slug flow; phase separation; two-phase flow.
\end{abstract}

\section{INTRODUCTION}

Two-phase gas and liquid flows are commonly found in many industrial applications, including oil refineries, natural gas processing plants, chemical plant and refrigeration systems [1]. T-junctions are employed for the partial phase separation of two phases, i.e., when the two-phase flow encounters a vertical T-junction, gas-rich stream flows into the branch arm, and liquid rich stream flows into the run arm. However, as the pressure in the run arm increases, the liquid is carried over into the branch arm along with the gas phase. As the downstream equipment was not compatible to handle excessive liquid, therefore, it causes the breakdown of downstream, resulting in frequent and unpredicted maintenance cost of the equipment [2-4]. Efforts have been made to increase the separation efficiency of a T-junction 
to make it applicable as a phase separator, for offshore and subsea application where space is limited for large conventional separators $[5,6]$.

Gas and Liquid flow passing through $\mathrm{T}$-junction experiences inevitable maldistribution of the phases [7]. Oranje [8] reported the phenomenon of maldistribution in a T-junction for the first time on a gas pipeline. He investigated the route preference of liquid condensate during the transport of natural gas in the natural-gas transportation pipeline network. The existence of liquid condensate in natural gas resulted in separation problems. All delivery stations were equipped with gas and liquid separators, but only a few collected liquid that could be attributed to an unequal phase splitting in T-junctions [9]. A survey of the current literature recommends that research has been made to contemplate the phase separation through $\mathrm{T}$-junctions both by experimental examination and theoretical analysis by carefully studying the geometry of $\mathrm{T}$-junction, fluid properties and flow parameters. Besides, this issue of phase maldistribution has been addressed in a few state of the art reviews, e.g., Muller and Reimann [10], Azzopardi [11] and Saieed et al. [12].

The process of phase separation in T-junction is a complex process because of the involvement of a large number of parameters that include geometrical parameters, flow parameters, and fluid properties. For the geometry alone there are eight parameters which are required, i.e., the diameter of main, run and branch arm, the length of main and branch arm, orientation angles of main, run and branch arm [13, 14]. A lot of research literature is available on altering the diameter ratio [15, 16], branch orientation [17], inlet flow regimes like stratified, stratified-wavy, and slug flow [18-20].

In order to improve the separation efficiency of $\mathrm{T}$-junction, several modifications were performed. Reimann [21] proposed a T-junction geometry by installing a separator vessel around the branch arm, efficiencies of $100 \%$ were claimed for specific flow rates approaching the T-junction. However, the efficiency dropped significantly by increasing the flow rates. Katsaounis et al. [22] proposed a T-junction based on the concept of dynamic phase separation by the reintroduction of liquid carried into the branch arm back to the main pipe, but not much of the information is available. Bevilacqua et al. [23] proposed comb separator by installing a combination of different $\mathrm{T}$-junction separators in series with upward branch arms. Wren [24] also combined two T-junctions placed in series, the branch arm of first $\mathrm{T}$-junction facing upward and branch arm of second $\mathrm{T}$-junction facing downward. Baker [25] used the same design and installed baffles inside the main pipe to improve the phase separation.

Yang et al. [26] proposed multi-tube T-junction separators with two and three layers and also introduced a new criterion, i.e., separation efficiency, for evaluating the phase separation effect of two-phase flows at T-junction. The separation efficiency was defined as the ratio of actual separation to the complete separation and is given in equation (19). The separation efficiency of multi-tube T-junction separator was higher than the simple Tjunction, and even complete phase separation was achieved for two-layer multi-tube combination. However, for the simple T-junction, the separation efficiency of more than $90 \%$ suggested by Wren and Azzopardi [27] is still a matter of research.

This paper presents a T-junction design with integrated expander section along the branch arm for effective separation of two-phase flow. The effect of different superficial gas and liquid velocity were investigated with air and water as working fluids in stratified, stratified-wavy and slug flows. The phase distribution in this T-junction with expander section after branch arm has been investigated and analyzed. The phase separation data has 
been plotted by a fraction of gas and liquid enters the branch arm to the run arm and also by plotting separation efficiency to the fracture of mixture mass taken off.

\section{T-JUNCTION WITH EXPANDER DESIGN FOR COMPLETE PHASE SEPARATION}

The phase separation through T-junction is complicated because of the involvement of a large number of parameters. The geometry of the T-junction includes eight parameters i.e. diameter of three pipes main arm $D_{1}$, run arm $D_{2}$, diameter of branch arm $D_{3}$, radius of curvature of the corner, the direction of two outlet pipes relative to the inlet pipe and the inclination of the inlet and one outlet pipe from the horizontal [9]. Then for the flow parameters which includes inlet flow rates of liquid and gas phase, the two pressure drops across the T-junction $\left(\Delta P_{12}\right.$ and $\left.\Delta P_{13}\right)$ and physical parameters such as the densities, viscosities and surface tension of the phases [26] as shown in Figure 1. The dominant forces controlling the phase separation across the T-junction are gravity, phase inertial forces, and pressure drop at the T-junction [28]. The gravity forces in case of vertical branch arm T-junction tends to act in favor of gas phase flowing into the branch arm and tends to keep the liquid phase flowing at the bottom. The liquid phase has to "climb-up" to reach the branch arm opening in order to be diverted into the branch arm. Another phenomenon which is commonly observed is that vertical Tjunctions are often used with reduced branch arm in order to obtain better phase separation. Compared to the regular T-junction, the travel time for the liquid to divert into the branch arm is shorter for reduced branch arm opening.

In Figure 2, novel T-junction design with vertical reduced branch arm, based on the concept of dynamic phase separation by Katsaounis et al., [22] has been presented. The major application of this T-junction has been to obtain complete phase separation for a wide range of flow patterns that include stratified, stratified-wavy, and slug flow. When two-phase flow encounters a T-junction gas phase enters into the branch arm because of its lower momentum flux and liquid tends to flow into the horizontal run arm because of higher momentum flux. However, due to the lower pressure in branch arm, some of the liquid is deflected into branch arm along with the gas phase. Later, this liquid will be collected into the expander section and re-routed back into the horizontal run arm through backflow pipe. The dry gas leaves the expander through the gas outlet available at the top of the expander.

The T-junction with expander section behaves like a combination of two T-junction in series with branch arms pointing in a vertical direction, as shown in Figure 3. At low split ratio, the gas phase diverted into the branch arm from both $\mathrm{T}$-junction. 


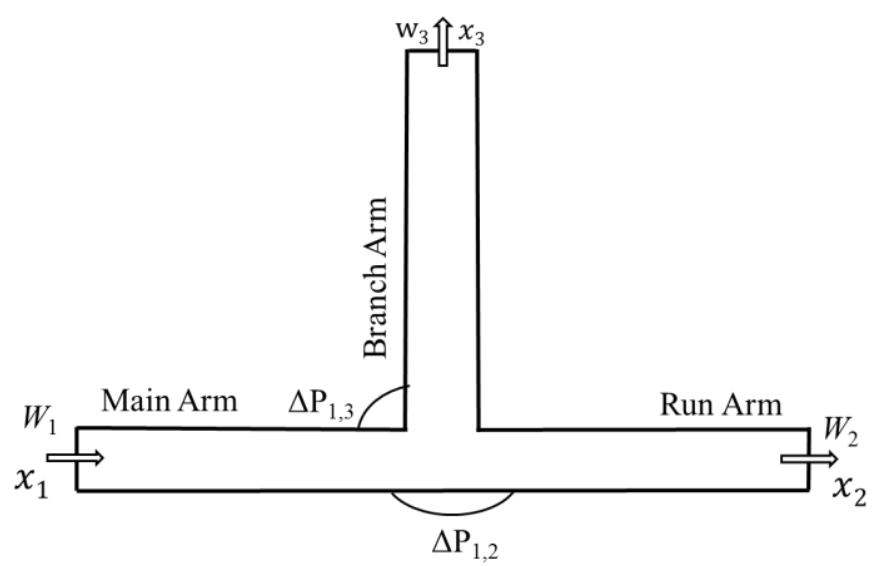

Figure 1. Regular T-junction design

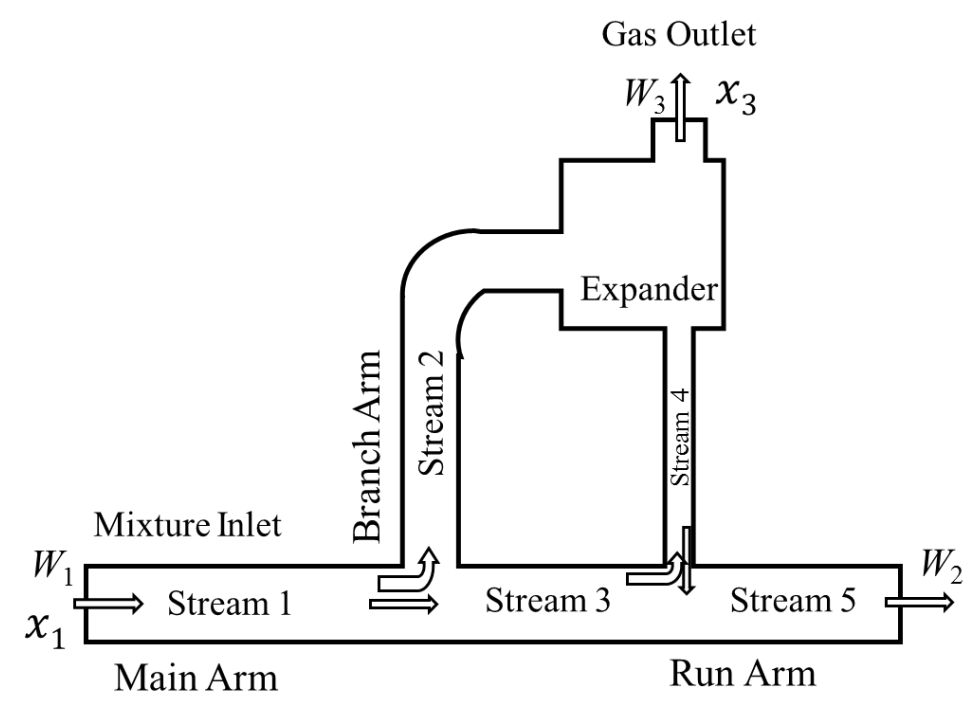

Figure 2. T-Junction with expander section.

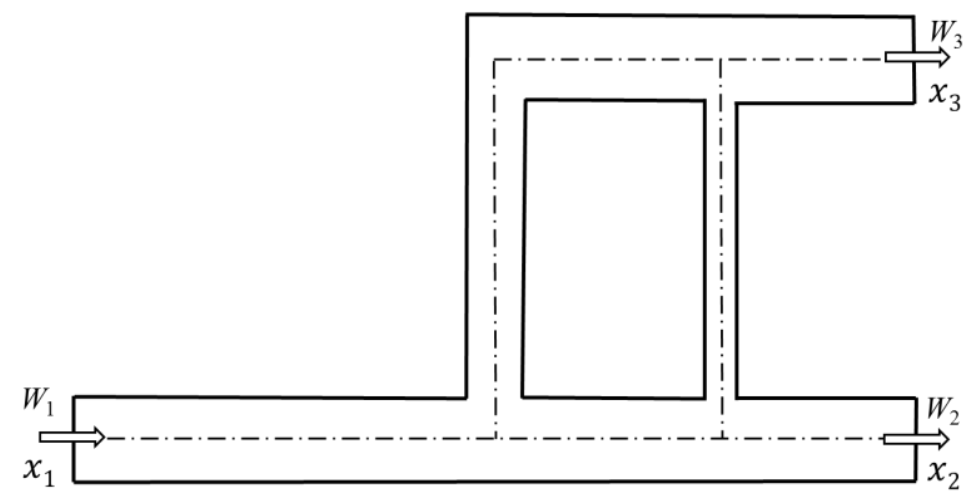

Figure 3. Combination of $\mathrm{T}$-junction in series with vertical branch arm. 
However, as the split ratio increase, the liquid is carried into the branch arm from first Tjunction and deflect back to main arm as it passes through second T-junction. Thereby providing the complete dry gas to the downstream equipment in stratified and stratified-wavy flow, and the improved phase separation in case of slug flow.

\section{EXPERIMENTAL SETUP}

The flow assurance multiphase flow facility employed in this study was a modified form that was described by Saieed [14]. The flow facility is capable of handling air and water as working fluid, the properties of air and water are listed in Table. 1.

Table 1. Physical properties of water and air (at $298 \mathrm{~K}$ and atmospheric pressure)

\begin{tabular}{cccc}
\hline No. & Fluid & Density $(\boldsymbol{\rho}) \mathbf{k g ~ m}^{-3}$ & Viscosity $(\boldsymbol{\mu}) \mathbf{~ k g ~}_{\left(\mathbf{m}^{-1} \mathbf{s}^{-1}\right)}$ \\
\hline 1 & Water & 1000 & $8.4 \times 10^{-4}$ \\
2 & Air & 1.225 & $1.8 \times 10^{-5}$ \\
\hline
\end{tabular}

The air/water flow facility used in the experiments was consists of horizontal pipes, constructed from acrylic and PVC pipes. The diameter of pipes is $0.074 \mathrm{~m}$ ID with a wall thickness of $0.003 \mathrm{~m}$ and is illustrated in Figure 4(a). The system consists of five horsepower two stage SWAN air compressor which is capable of delivering $0.9 \mathrm{~m}^{3} / \mathrm{min}$ at a working pressure of 8 bar. The air is filtered and cleaned before it supplied to the two-phase mixture. The inlet flow rate $\left(W_{\mathrm{G} 1}\right)$ to the mixture is controlled by a throttle valve, and the flow rate was metered by using calibrated rotameter. Water is taken from the storage tank, filled by tap water and is extracted into the mixing unit by employing three horsepower, three phases $(415,50 \mathrm{HZ})$ TECO centrifugal pump of $1450 \mathrm{rpm}$ and is capable of delivering water at a maximum flow rate of $0.0167 \mathrm{~m}^{3} / \mathrm{sec}$, with $8-10 \mathrm{~m}$ of pressure head. The inlet water flow rate is controlled by a gate valve and loop bypass valve. The flow rate was metered by NEWFLOW rotameter just before the mixer. The flow meter has a connection size of $0.074 \mathrm{~m}$ and is of a range between $0.00133-0.0133 \mathrm{~m}^{3} / \mathrm{sec}$. The two separate phases' air and water are then mixed in the mixing unit, which consists of mixing tee. From the mixing unit, the twophase mixture flows along the straight length of approximately 82 tube diameters of acrylic pipe in order the two-phase flow to be fully developed before reaching the test section. At the downstream of the test section the flow, further flows along $2.5 \mathrm{~m}$ in the horizontal and vertical section before reaching to the storage tank and the separation tank.

The T-junction used in the present study was made of PVC pipe having a diameter of $0.074 \mathrm{~m}$ in main and run arm and the length of each arm is $1 \mathrm{~m}$. The diameter of the branch arm is $0.0508 \mathrm{~m}$, and the diameter of the backflow pipe is $0.0254 \mathrm{~m}$. The pressure sensors are used at the inlet and two outlets of junctions to measure the gauge pressure at the inlet and outlets of the T-junction. Valves are used at the exit of run arm and branch arm to control the pressure and flow. For selected flow conditions in the inlet (pressure $P_{1}$, mass flux, quality $x_{1}$ ), the mass flux ratio was varied between zero (closed branch valve) and unity (closed run valve). The air and water exiting from the run arm are collected in the liquid hold-up tank, water is again circulated by a centrifugal pump, and air is vented to the atmosphere. 


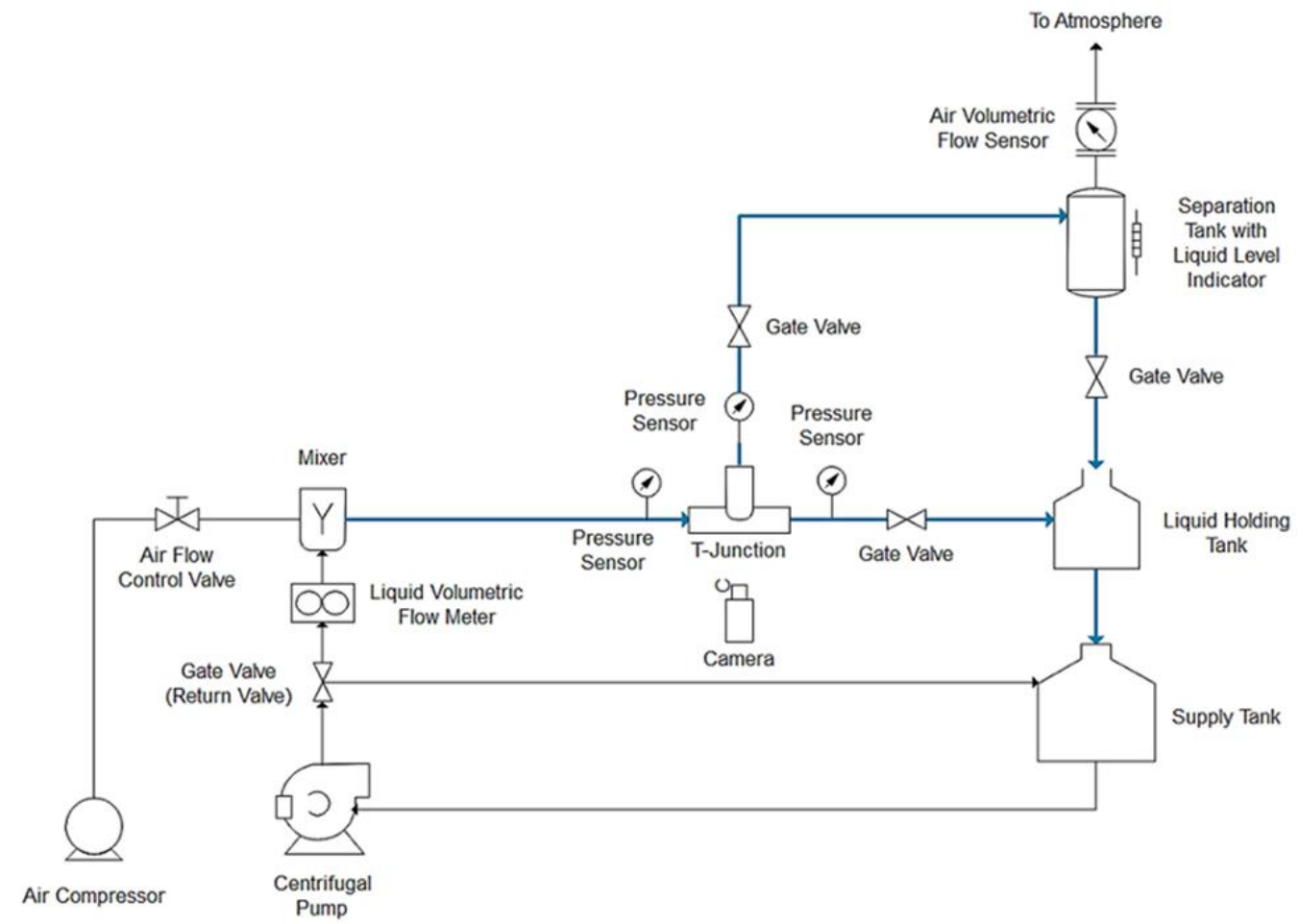

Figure 4(a). Schematic diagram of two-phase experimental flow loop.

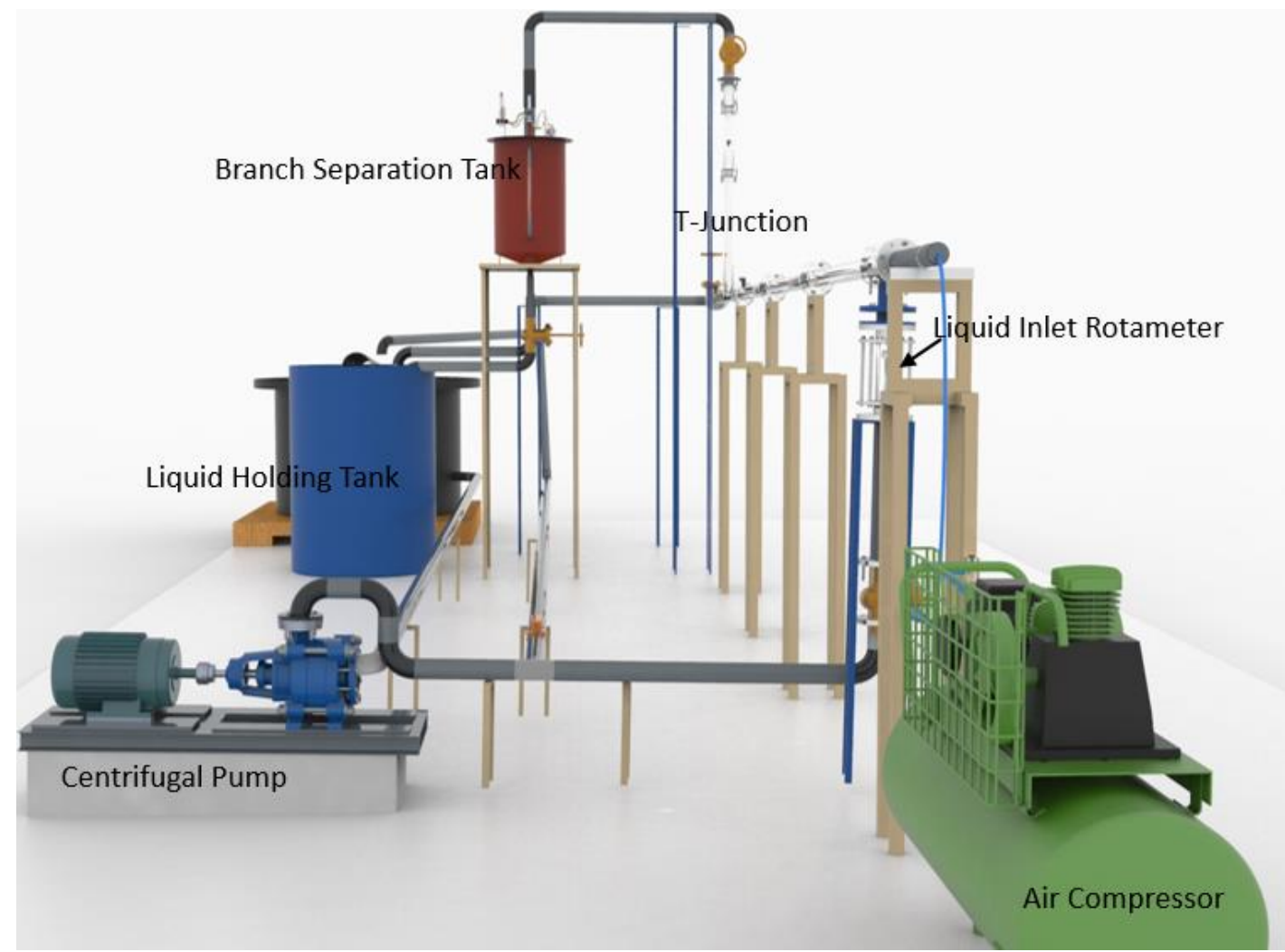

Figure 4(b). 3-D View of two-phase flow loop system. 
All pipes from the mixing unit to the test had an internal diameter of $0.074 \mathrm{~m}$ and were made from acrylic pipes, and piping used downstream of the test section diameter and are made of PVC. At the junction the flow is split into two streams, one stream flows in a straight horizontal direction along the run arm of the T-junction, and other stream flows vertically upward through the branch arm. The air-water two-phase flow is exiting from branch arm outlet collected into the branch separation tank, where both phases are separated and metered. Air vented to the atmosphere through the top of the separation tank and is metered by a combination of rotameters and will give the value of $W_{\mathrm{G} 3}$. The water collected also measured, giving us the value of $W_{\mathrm{L} 3}$ and then this water supplied to the liquid holdup tank.

At the downstream of the T-junction, gate valves are installed. The purpose of the valves at each outlet is to divide the flow between the run arm and branch arm. Increasing the resistance in the run arm increases the flow split and increases the pressure; this was done in order to replicate the effect of industrial equipment.

\section{VALIDATION}

To test the reliability and performance of the present experimental setup, a benchmark analysis was carried out to validate the Experimental flow loop installed at Flow Assurance at UTP (Malaysia). For this, data was selected from Saieed [1] experimental study at slug flow pattern. The parameters in both studies kept constant. The T-junction with diameter ratio $(\mathrm{DR}=1)$ has been selected and installed to the flow loop. The experiment for the validation was run and data collected to validate and test that the installed experimental flow loop setup produce acceptable data. The diameter of the pipes and geometry of the T-junction especially $(\mathrm{DR}=1)$, pressure and temperature are matched in both studies. However, the superficial velocities of both phases in case Saieed [1] are higher in comparison to the present study. Liu and Li [29] stated that flow separation in T-junction is governed by phase inertia difference [30]. This inertia difference can be interpreted in terms of gas to liquid phase velocity ratio. Thus, by similar velocity ratio, two sets of phase separation data can be compared. The velocity ratio (VR) can be calculated from the following expression,

$$
V R=\frac{U_{S A}}{U_{S W}}
$$

Figure 5 shows a comparison between the present study and data from Saieed study [1]. The agreement between both the experimental results appears to be quite fair with an average difference of $4.0 \%$. This comparison accounts for the different superficial velocities of the gas and liquid phase in both studies. According to Azzopardi [11], liquid carry-over increases with increasing the velocity of the gas. As in the present case, the air velocity is lower than the experimental data used by Saieed [1]. However, the observed trend is acceptable. 


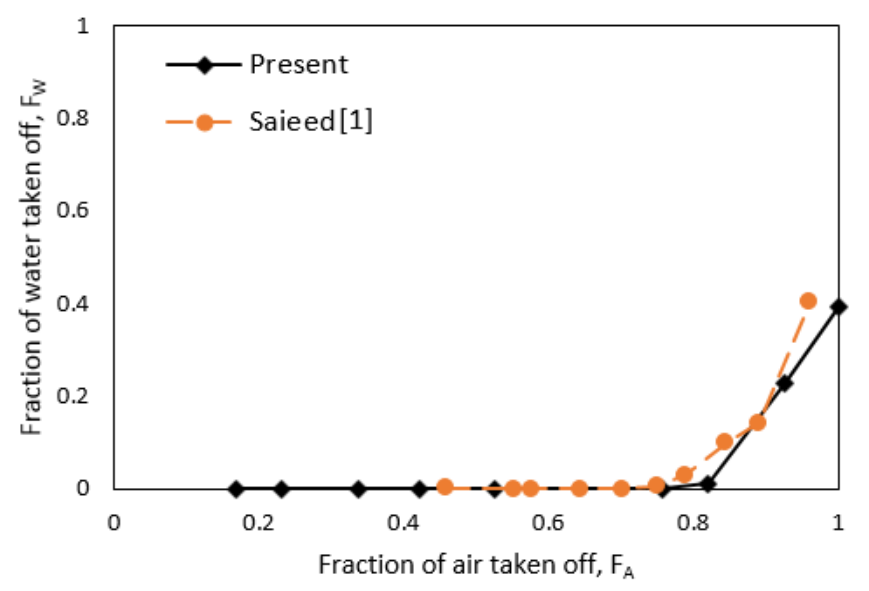

Figure 5. Phase separation data for present study at $U_{\mathrm{SA}}=0.33 \mathrm{~m} / \mathrm{s}, U_{\mathrm{SW}}=0.477 \mathrm{~m} / \mathrm{s}$, and Saieed [1] $U_{\mathrm{SA}}=0.648 \mathrm{~m} / \mathrm{s}, U_{\mathrm{SW}}=0.84 \mathrm{~m} / \mathrm{s}$ at regular T-Junction of $\mathrm{DR}=1$.

\section{REPRESENTATION OF PHASE-SEPARATION DATA}

The quantities used in two-phase flow are defined in the following way, [31]

The mass flow rates of the gas $\left(W_{\mathrm{G}}\right)$ and liquid $\left(W_{\mathrm{L}}\right)$ are defined by,

$$
W_{G}=\rho_{G} A U_{S G} \text { and } W_{L}=\rho_{L} A U_{S L}
$$

Superscript ' $G$ ' and ' $L$ ' represent the gas and liquid phase.

Total mass flow rate is given by,

$$
W=W_{G}+W_{L}
$$

The Mass flux is given,

$$
\begin{gathered}
G_{G}=\frac{W_{G}}{A} \text { and } G_{L}=\frac{W_{L}}{A} \\
G_{T P}=G_{G}+G_{L}
\end{gathered}
$$

' $A$ ' represents the area of the pipe and superscript ' $T P$ ' represent two-phase mixture.

The volume flow rate is given by,

$$
\begin{gathered}
Q_{G}=\frac{W_{G}}{\rho_{G}} \text { and } Q_{L}=\frac{W_{L}}{\rho_{L}} \\
A=A_{L}+A_{G}
\end{gathered}
$$

Volume flux is given by,

$$
\begin{aligned}
J_{L}=\frac{Q_{L}}{\rho_{L}} J_{G} & =\frac{Q_{G}}{\rho_{G}} \text { and } J_{L}=\frac{Q_{L}}{\rho_{L}} \\
J_{T P} & =J_{G}+J_{L}
\end{aligned}
$$

In-situ local velocity,

$$
U_{G}=\frac{Q_{G}}{A_{G}} \text { and } U_{L}=\frac{Q_{L}}{A_{L}}
$$

The total area occupied by the liquid and gas phase is given by,

$$
A=A_{L}+A_{G}
$$


Superficial gas and liquid velocity,

$$
U_{S G}=\frac{Q_{G}}{A} \text { and } U_{S L}=\frac{Q_{L}}{A}
$$

Quality at the inlet of the mixing unit,

$$
x_{1}=\frac{G_{G}}{G_{T P}}=\frac{G_{G}}{G_{G}+G_{L}}=\frac{W_{G}}{W_{T P}}=\frac{W_{G}}{W_{G}+W_{L}}
$$

The two-phase void fraction can be calculated from liquid hold up $\left(H_{L}\right)$;

Void Fraction $(\alpha)$,

$$
<H_{L}>=\frac{V_{L}}{V_{L}+V_{G}}
$$

$$
<\alpha>=1.0-H_{L}
$$

The density of two-phase mixture,

$$
\rho_{T P}=\alpha \rho_{G}+(1-\alpha) L
$$

In accordance with Figure 1,

$$
G_{1} A_{1} x_{1}=G_{2} A_{2} x_{2}+G_{3} A_{3} x_{3}
$$

' $x$ ' represents the quality of gas and ' $G$ ' represents mass flux.

For perfect phase separation

$$
\frac{x_{3}}{x_{1}}=\left(\frac{G_{3}}{G_{1}}\right)^{-1}=\left(\frac{W_{3}}{W_{1}}\right)^{-1}
$$

Separation Efficiency of T-junction is given in terms of the fraction of gas in branch arm $\left(F_{\mathrm{BG}}\right)$ and the fraction of liquid in side $\operatorname{arm}\left(F_{\mathrm{BL}}\right),[26]$

$$
\eta=\frac{L}{L_{\max }}=\left|F_{B G}-F_{B L}\right|
$$

\section{RESULTS AND DISCUSSION}

The experimental investigation was carried at different superficial gas and liquid velocities. The superficial gas velocity ranges from $0.25-1.40 \mathrm{~m} / \mathrm{s}$, and the superficial liquid velocity ranges from $0.14 \mathrm{~m} / \mathrm{s}-0.78 \mathrm{~m} / \mathrm{s}$. In this study of the two-phase separation, thirteen groups of tests were performed, and each group of test consisted of particular inlet gas and liquid superficial velocity. In each experiment, the mass split $\left(W_{3} / W_{1}\right)$ was varied from 0 to 1 . The pressure and the temperature during the experiments were kept at $25^{\circ} \mathrm{C}$. The air is considered as a gas phase and water as a liquid phase with physical properties as described already in Table 1.

\section{Flow Pattern}

The inlet rates of water (liquid phase) and air (gas phase) at which data was taken were plotted on the Taitel and Dukler map [32]. The flow pattern approaching the T-junction was visually observed to be stratified, stratified-wavy and the slug flow as can be seen through acrylic pipes shown in Figure 6. This was verified by plotting the experimental data, i.e. superficial 
gas and liquid velocities on Taitel and Dukler map [32] in Figure 7. It accurately matches with the visual observation during experimentation and the flows obtained are turned out to be the stratified, stratified-wavy and slug flow and are represented by red circular shapes on Taitel and Duckler map in Figure 7. Almost thirteen different velocity combinations for gas and liquid phase selected for this study and is shown in Table 2, to investigate their effect on the upstream flow pattern and on phase separation behaviour of the T-junction.

(a). Stratified Flow

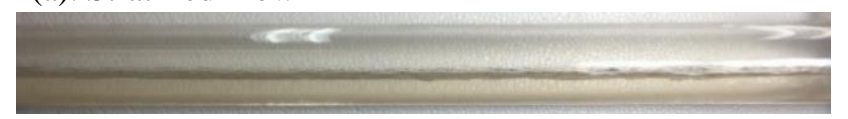

(b). Stratified-wavy Flow

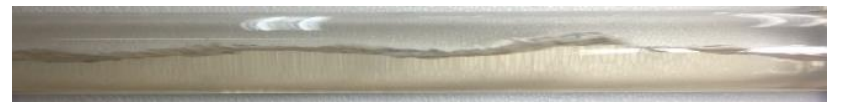

(c). Slug Flow

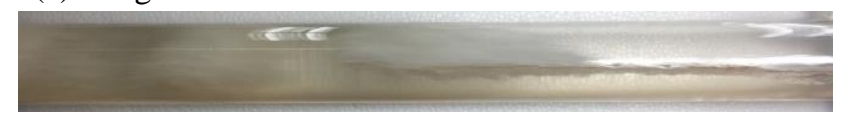

Figure 6. Flow patterns observed during Experiment

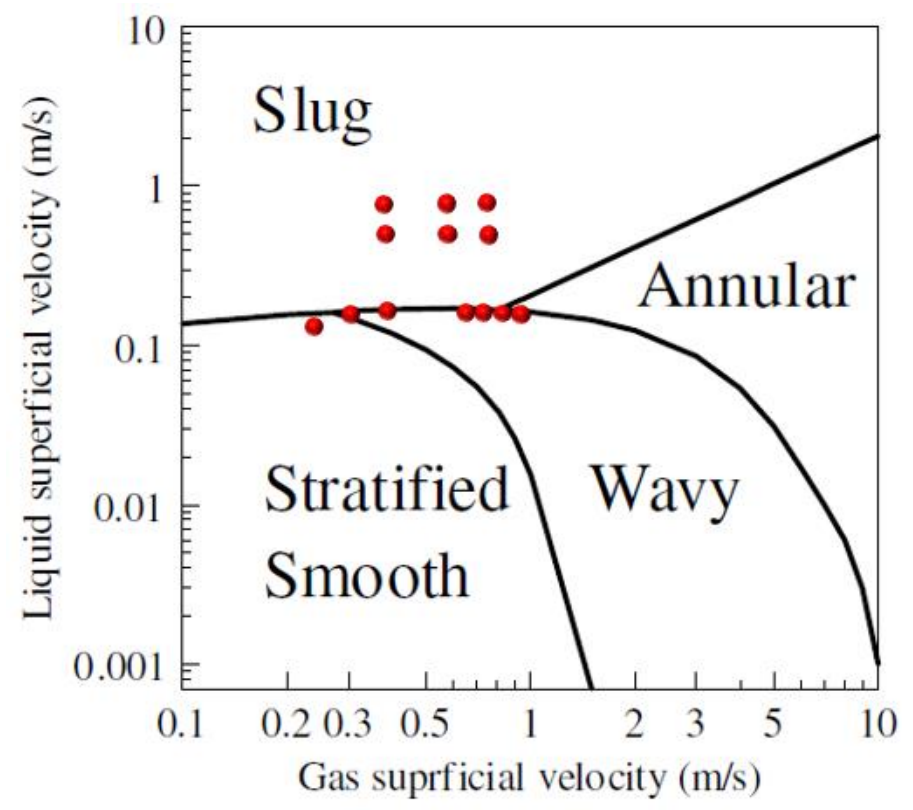

Figure 7. Taitel and Dukler [32] Flow pattern map showing the inlet conditions on $0.074 \mathrm{~m}$ horizontal pipe. 
Table 2. Inlet conditions for phase for the phase separation analysis.

\begin{tabular}{ccccc} 
Test Case & $\boldsymbol{U}_{\text {SA }}$ & $\boldsymbol{U}_{\text {Sw }}$ & VR & Flow Pattern \\
\hline 1 & 0.25 & 0.14 & 1.8 & Stratified \\
2 & 0.33 & 0.15 & 2.2 & Stratified \\
3 & 0.47 & 0.19 & 2.4 & Stratified-wavy \\
4 & 0.70 & 0.19 & 3.6 & Stratified-wavy \\
5 & 0.93 & 0.19 & 4.8 & Stratified-wavy \\
6 & 1.16 & 0.19 & 6.0 & Stratified-wavy \\
7 & 1.40 & 0.19 & 7.2 & Stratified-wavy \\
8 & 0.47 & 0.39 & 1.2 & Slug \\
9 & 0.47 & 0.58 & 0.8 & Slug \\
10 & 0.47 & 0.78 & 0.6 & Slug \\
11 & 0.70 & 0.39 & 1.8 & Slug \\
12 & 0.70 & 0.58 & 1.2 & Slug \\
13 & 0.70 & 0.78 & 0.9 & Slug \\
\hline
\end{tabular}

\section{Effect of Inlet Gas and Liquid Superficial Velocities}

Phase separation through vertical T-junction is governed by the competing inertia, centripetal and gravitational forces. As the inertia and gravitational forces add each other and dominate during two-phase flow. The centripetal force caused by bending of the gas phase into the branch arm does not produce enough under pressure for the liquid to be carried over in stratified and stratified-wavy flow. In the case of stratified and stratified-wavy flow. It is quite evident from Figure 8 that T-junction with expander section produces complete phase separation. Varying the gas phase velocity has a negligible effect on phase separation for all combination of the phase velocities in stratified and stratified-wavy flow. In case of stratified flow at a superficial gas velocity of $0.25 \mathrm{~m} / \mathrm{s}$ and $0.33 \mathrm{~m} / \mathrm{s}$, when the resistance in the run arm increases the amount of the gas phase in the branch arm increases. However, the liquid is carried into the branch arm and then collected into the expander section, thereby, increasing further separation between two phases. The liquid is reintroduced into the main arm through backflow pipe. Thus complete phase separation of two phases occurs. Increasing the superficial gas velocity from $0.25 \mathrm{~m} / \mathrm{s}$ to $0.33 \mathrm{~m} / \mathrm{s}$ and superficial liquid velocity from 0.14 $\mathrm{m} / \mathrm{s}$ to $0.15 \mathrm{~m} / \mathrm{s}$ does not produce any effect on the phase separation behavior, leading to the complete phase separation between gas and liquid phase and is shown in Figure 8(a). Moreover, the gas threshold value in the case of stratified flow reaches to $100 \%$. This indicates that when $100 \%$ gas phase collected at the exit of branch arm, no liquid carried along with the gas phase. 

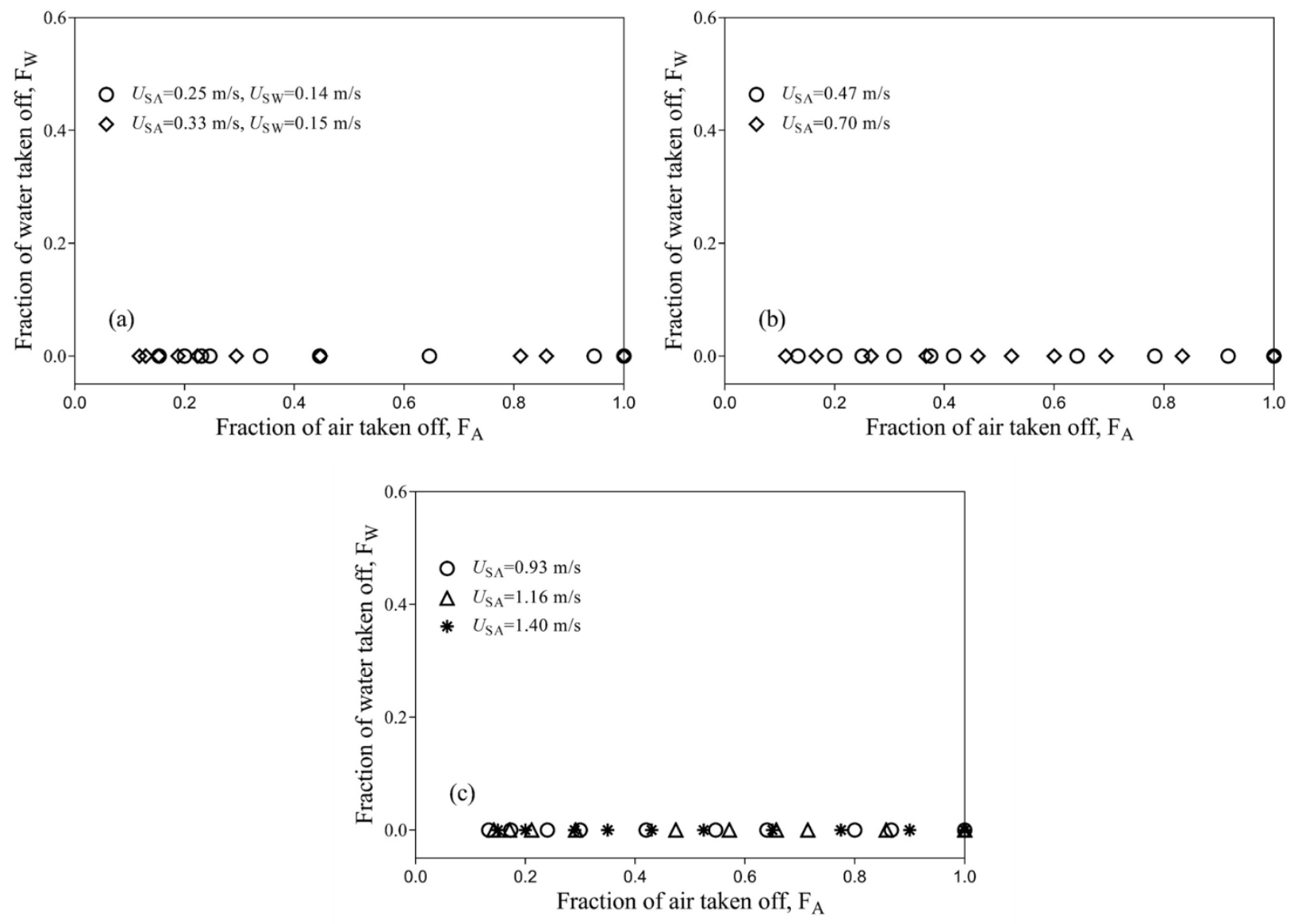

Figure 8. Phase separation behavior in (a) stratified flow (b) stratified-wavy flow at a constant superficial liquid velocity of $0.19 \mathrm{~m} / \mathrm{s}$

Similar results have been obtained for the stratified-wavy flow. Five tests cases were performed for the stratified-wavy flow at the superficial gas velocities of $0.47 \mathrm{~m} / \mathrm{s}, 0.70 \mathrm{~m} / \mathrm{s}$, $0.93 \mathrm{~m} / \mathrm{s}, 1.16 \mathrm{~m} / \mathrm{s}, 1.40 \mathrm{~m} / \mathrm{s}$ at the liquid velocity of $0.19 \mathrm{~m} / \mathrm{s}$. The tested T-junction produces the complete phase separation, separating the liquid and gas phase. Like stratified flow, a similar trend has been obtained in stratified-wavy flow and is shown in Figure 8(b) and (c). It was found that variation in superficial gas velocity by keeping the superficial liquid velocity constant does not produce any effect on the phase separation behavior. In Figure 8, all the data points lie on the horizontal axis. As the mass split ratio increases between branch to main arm, it increases the fraction of air into the branch arm until air fraction into the branch becomes equal to the air fraction into main arm, i.e., complete phase separation occurs.

During the experiment it has been observed that liquid is carried into the branch arm but is collected into the expander section and re-routed into the run arm thereby, providing complete dry air downstream of the branch arm.

The case of slug flow is different from the stratified and stratified-wavy flow. As slug flow is dominated by large elongated Taylor bubbles and liquid slug. Thereby causing huge pressure 
fluctuations in the pipeline. Unlike stratified and stratified-wavy, Figure 9 shows that complete phase separation has not been achieved in slug flow. However, phase separation improves in $\mathrm{T}$-junction with expander section compared to the regular and reduced $\mathrm{T}$ junction. It can be seen from Figure 9(a), (b) and (c) that the gas threshold of $80 \%$ is observed for all the velocity combinations in the slug flow.

For the lowest superficial liquid velocity of $0.39 \mathrm{~m} / \mathrm{s}$ at a constant superficial gas velocity of $0.47 \mathrm{~m} / \mathrm{s}$ as shown in Figure 9(a), the gas threshold of $90 \%$ is obtained. That shows, $90 \%$ of the gas flows into the branch arm without liquid being carried over into the branch arm. However, as the liquid velocity increased to $0.58 \mathrm{~m} / \mathrm{s}$ and $0.78 \mathrm{~m} / \mathrm{s}$, the liquid carry-over decreases but also gas phase threshold decreases. Similar observations have been made for the liquid velocities $0.39-0.77 \mathrm{~m} / \mathrm{s}$ at a superficial gas velocity of $0.7 \mathrm{~m} / \mathrm{s}$.

\section{Effect of Expander Section}

Two-phase flow split at the T-junction with expander section suggests that complete phase separation can be achieved in case of stratified and stratified-wavy and enhanced phase separation in case of slug flow. The effect of the T-junction geometry can be seen in Figure 9, and as well in the separation efficiency graph, as shown in Figure 11. In case of stratified flow with superficial gas velocity of $0.25 \mathrm{~m} / \mathrm{s}$ and $0.33 \mathrm{~m} / \mathrm{s}$ and superficial liquid velocity of $0.14 \mathrm{~m} / \mathrm{s}$ and $0.15 \mathrm{~m} / \mathrm{s}$, the phase separation efficiency up to $100 \%$ has been achieved. Similarly, for stratified-wavy flow at gas superficial velocity varying from of $0.47 \mathrm{~m} / \mathrm{s}-1.40$ $\mathrm{m} / \mathrm{s}$ at the constant liquid velocity of $0.19 \mathrm{~m} / \mathrm{s}$, separation efficiency up to $100 \%$ have also been witnessed.

T-junction with expander section and backflow pipe behaves like two T-junction in series as shown in Figure 3, thereby, improving the phase separation of two phases. At low extraction ratio, the fraction of air is exiting from the branch arm as well as from backflow pipe. However, at higher extraction of air into branch arm, the water is carried into branch arm and is collected into the expander section. Water is re-routed into main arm through back flow pipe. In case of stratified and stratified-wavy flow, water has lower momentum and water is re-introuduced back into main pipe before expander fills completely with water. But the case of slug flow is different than stratified and stratified-wavy flow the expander is filled with water before all the water re-introduced back into main pipe. Thus liquid is carried into the downstream once the expander is filled with water. 

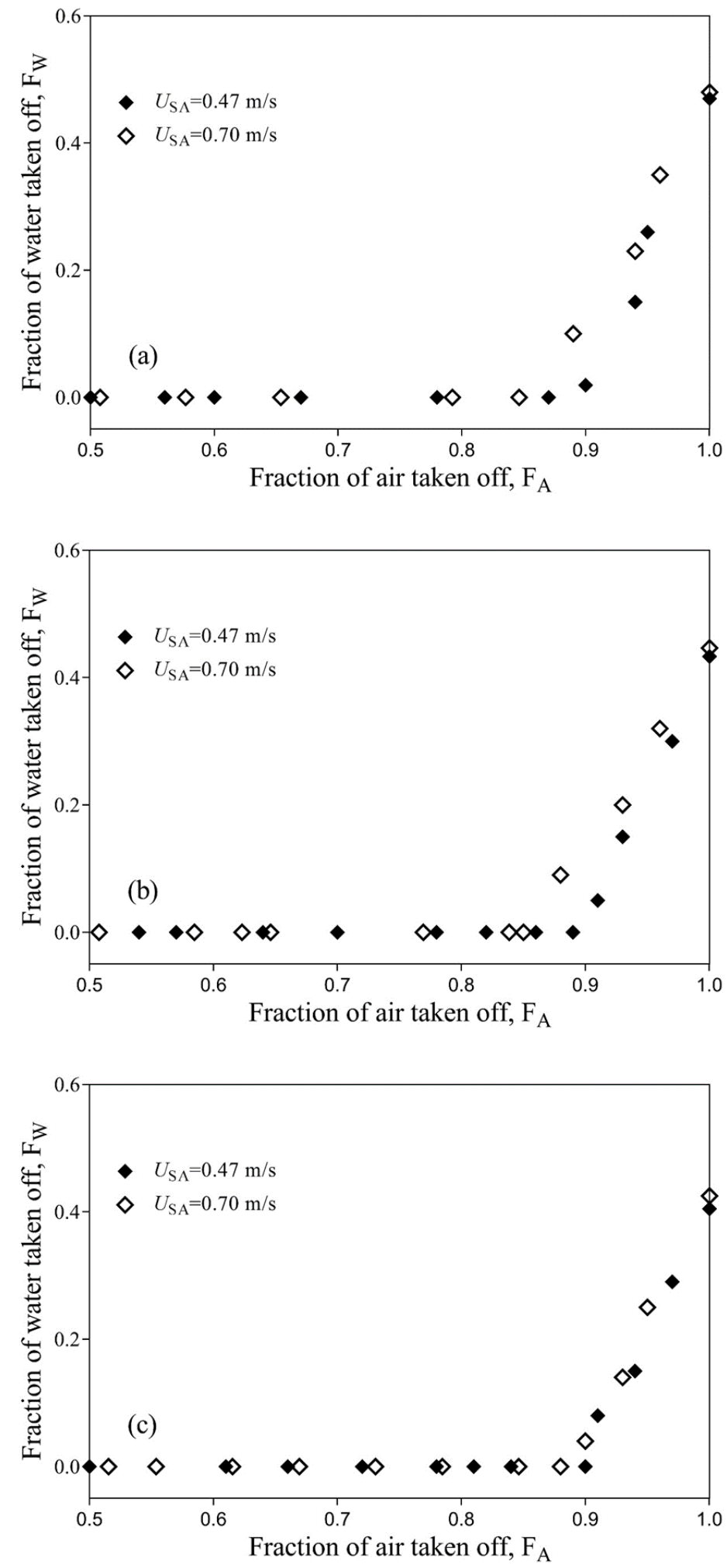

Figure 9. Phase separation behavior in slug flow wavy flow at liquid superficial velocity of (a) $U_{\mathrm{SW}}=0.39 \mathrm{~m} / \mathrm{s}$ (b) $U_{\mathrm{SW}}=0.58 \mathrm{~m} / \mathrm{s}$ (c) $U_{\mathrm{SW}}=0.78 \mathrm{~m} / \mathrm{s}$ 
The phase separation efficiency is shown in Figure 10. It is shown in Figure 10 that in case of stratified and stratified-wavy flow, with an increase in the fraction of mixture mass taken off in the branch arm the separation efficiency increases and complete phase separation occurs. But in case of slug flow with the increase in mixture mass taken off $\left(W_{3} / W_{1}\right)$ in the branch arm first the efficiency increases but then it reduces as the liquid carry-over increases. This has been plotted in Figure 10. In case of stratified and stratified-wavy in Figure 10(a) and (b), all the data points lie on the vertical axis and it achieves the $100 \%$ separation efficiency. However, in Figure 10(c) and (d) at the superficial gas velocity of $0.47 \mathrm{~m} /$ and $0.70 \mathrm{~m} / \mathrm{s}$ it achieves the phase separation efficiency of $90 \%$ for the liquid flow rate of 0.39 $\mathrm{m} / \mathrm{s}$ and complete phase separation does not occur. As the fraction of mixture taken off into branch increases liquid carry-over tends to start, and the separation efficiency drops to $40 \%$ in some cases.
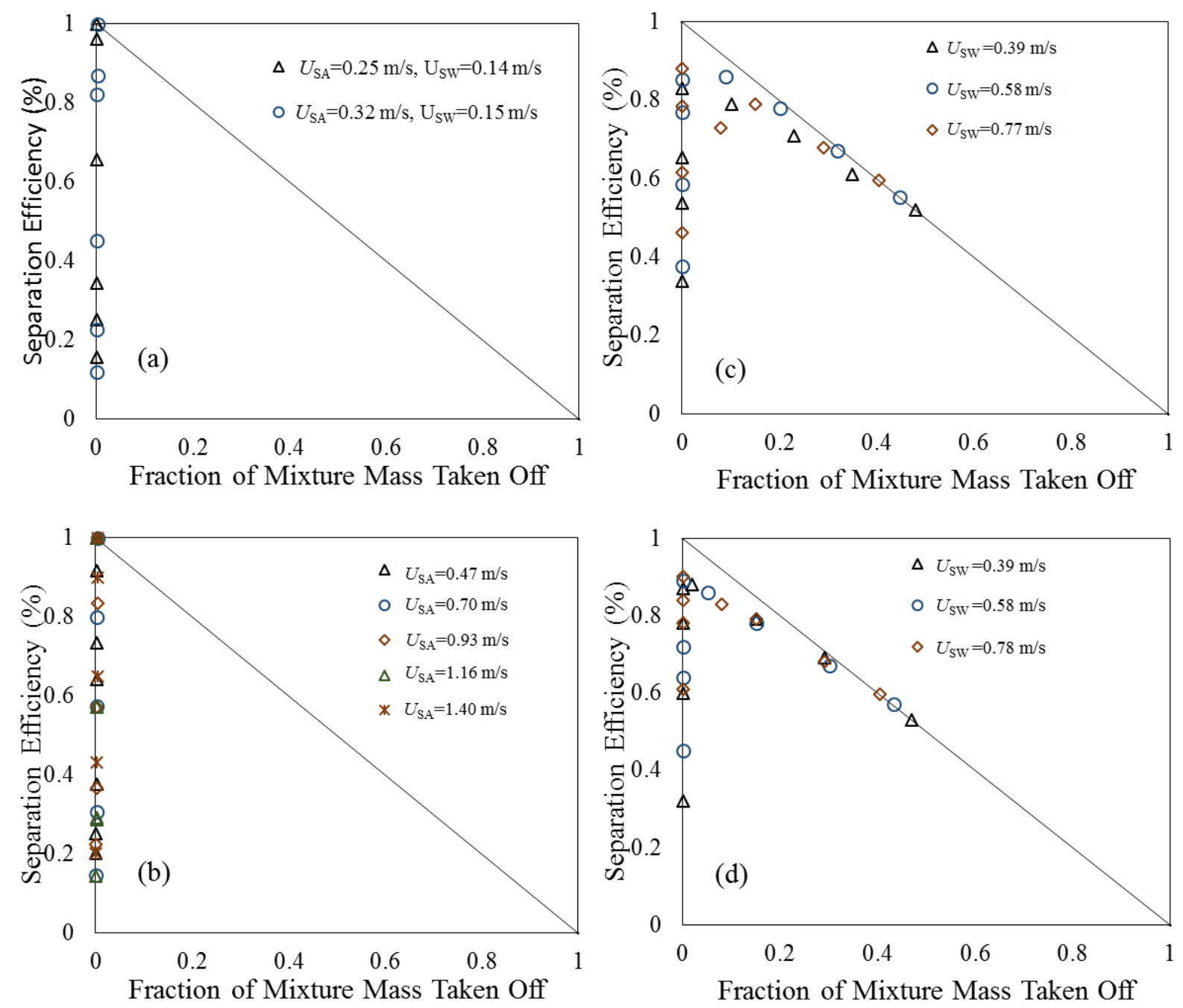

Figure 10. Separation efficiency vs Fraction of mass taken off for (a) stratified flow (b) stratified-wavy (c) and (d) slug flow at $0.47 \mathrm{~m} / \mathrm{s}$ and $0.70 \mathrm{~m} / \mathrm{s}$. 
However, increasing the inlet liquid flow gas threshold decreases, but phase separation improves by reducing the liquid carry-over, and complete phase separation was not achieved. The wren and Azzopardi [26] suggested that criterion for T-junction to be considered as serious partial phases separator, $10 \%$ by volume of unwanted phase should not go with the preferred phase, this criteria has been achieved in this T-junction at superficial gas velocity of $0.47 \mathrm{~m} / \mathrm{s}$ and superficial liquid velocity of $0.39 \mathrm{~m} / \mathrm{s}$.

\section{COMPARISON WITH PUBLISHED DATA}

The T-junction with expander section has been compared with simple T-junction of reduced branch arm having a diameter ratio of 0.67 from Saieed [1] experiments. In both the data, the velocity ratios have been matched. It has been observed from Figure 11 that in case of Saieed [1] for stratified-wavy flow when $70 \%$ of gas phase is taken into the branch arm no liquid is carried over, further increasing the gas phase split into the branch arm liquid is carried and maximum of $18 \%$ is taken when complete gas phase enters into the branch. But in the present study of T-junction with expander section with same diameter ratio complete phase separation occurs and no liquid enters into the branch arm at any velocity, as shown in Figure $8(\mathrm{a}),(\mathrm{b})$, and (c).

In the case of slug flow, as mentioned earlier, complete phase separation could not have been achieved because of its complicated nature. However, liquid threshold increases, in the case of Saieed [1] liquid threshold is around $80 \%$, but in the present study, it is around $88 \%$. Here, one important point for consideration is that when once liquid start to carry over, the amount of liquid carry-over in both the cases is almost same, so the liquid carry-over when $100 \%$ of the gas phase flow into the branch arm in slug flow is the same for the simple T-junction and the $\mathrm{T}$-junction with the expander section. 

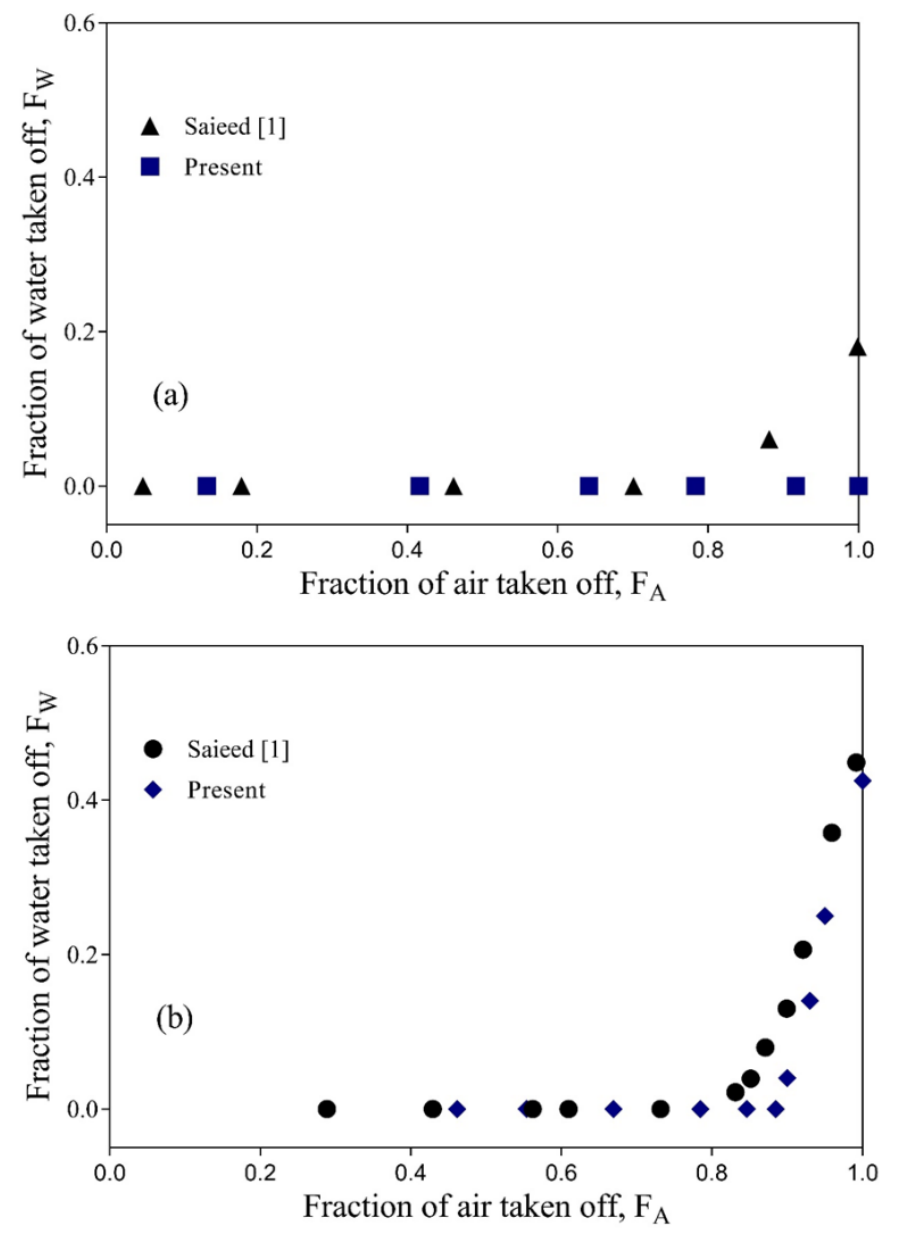

Figure 11. Comparison of data with simple T-junction data of Saieed [1] versus T-junction with Expander for (a) stratified-wavy (b) slug flow

\section{CONCLUSION}

Effect of different inlet conditions under the stratified, stratified-wavy and slug flow patterns on phase separation has been investigated at T-junction with expander section using air and water as working fluids. From the above results and discussions, the following conclusions are drawn.

- Comparison to the simple T-junction, the T-junction with expander section produces complete phase separation for stratified and stratified-wavy flow for all superficial liquid and gas velocities.

- Enhanced phase separation is achieved in slug flow.

- The phase separation criterion of less than $10 \%$ liquid in gas stream achieved is achieved for stratified, stratified-wavy and slug flow.

- T-junction with expander section behaves like a combination of two T-junction in series with vertical branch arms. 
- Increasing the superficial liquid increases the phase separation efficiency and increasing the gas superficial velocity decreases the phase separation efficiency.

\section{ACKNOWLEDGEMENT}

The authors would like to acknowledge the funding by Ministry of Higher Education through FRGS 0153AB-L03 and PETRONAS through YUTP Fundamental Research Grant 0153AAE03.

\section{REFERENCES}

[1] Saieed A. Experimental investigation on the effect of diameter ratio on two-phase separation in a T-junction. Universiti Teknologi Petronas (UTP), Malaysia; 2017.

[2] Pao W, Hashim FM, Ming LH. Numerical investigation of gas separation in Tjunction. In AIP Conference Proceedings: AIP Publishing; 2015.

[3] Dos Reis E, Goldstein L. Fluid dynamics of horizontal air-water slug flows through a dividing T-junction. International Journal of Multiphase Flow 2013; 50:58-70.

[4] Tran M, Memon Z, Saieed A, Pao W, Hashim F. Numerical simulation of two-phase separation in T-junction with experimental validation. Journal of Mechanical Engineering and Sciences 2018;12:4216-4230.

[5] Memon ZQ, Tran CM, Pao W, Hashim FM. Two-phase slug flow separation at Tjunction with regular and reduced vertical side arm. In AIP Conference Proceedings: AIP Publishing; 2018.

[6] Sam B, Pao W, Nasif MS, Norpiah RBM. Simulation of two phase oil-gas flow in Tjunction. ARPN Journal of Engineering and Applied Sciences 2016;11:1201112016.

[7] Saieed A, Pao W, Ali HM. Prediction of phase separation in a T-Junction. Experimental Thermal and Fluid Science 2018;97:160-179.

[8] Oranje L. Condensate behavior in gas pipelines is predictable. Journal Oil \& Gas 1973;71:39-44.

[9] Saieed A, Pao W, Hewakandamby B, Azzopardi BJ, Wood DA, Ali HM. Experimental investigation on the effect of diameter ratio on two-phase slug flow separation in a T-Junction. Journal of Petroleum Science and Engineering 2018;170:139-150.

[10] Muller U, Reimann J. Redistribution of two-phase flow in branching conduits: a survey. In: 1st International Conference on Multiphase Flows, pp. 24-27; 1991.

[11] Azzopardi BJ. Phase separation at T-junctions. Multiphase Science and Technology 1999;223-329.

[12] Saieed A, Sam B, Pao W, Hashim FM, Norpiah, RBM. A review of T-junction geometrical effect on two-phase separation. ARPN Journal of Engineering and Applied Sciences 2016;11:14233-14238.

[13] Rea S, Azzopardi BJ. The split of horizontal stratified flow at a large diameter Tjunction. Chemical Engineering Research and Design 2001;79:470-476.

[14] Saieed A, Pao W, Hashim, F.M. Effect of T-junction diameter ratio on stratified-wavy flow separation. Journal of Natural Gas Science and Engineering 2018;51:223-232. 
[15] Pao W, Saieed A, Hashim FM, Norpiah RBM. Numerical simulation of two-phase separation in a small diameter ratio T-junction. Materialwissenschaft und Werkstofftechnik 2017;48:255-260.

[16] Azzopardi BJ. The effect of side arm diameter on phase split at T-junctions. In: SPE Annual Technical Conference and Exhibition; 1999.

[17] Saieed A, Sam B, Pao W, Hashim FM. Numerical investigation of side arm gas volume fraction in two phase T-junction. Journal of Mechanical Engineering and Sciences 2016;10:2311-2323.

[18] Tran M, Memon, Z, Pa, W, Hashim, FM. Preliminary results of numerical simulation of slug flow in a regular T-junction. In MATEC Web of Conferences; 2018.

[19] Yang L, Azzopardi BJ, Belghazi A, Nakanishi S. Phase separation of liquid-liquid two-phase flow at a T-junction. AIChE Journal 2006;52:141-149.

[20] Tae SJ, Cho K. Two-phase flow distribution and phase separation through both horizontal and vertical branches. KSME International Journal 2003;17:1211-1218.

[21] Reimann J. A new gas separator for stratified and slug flow. In 3rd International Conference on Multiphase Flow, The Hague, Netherlands; 1987.

[22] Katsaounis A, Papanikas D, Fertis D, Margaris D. Dynamic T-junction separator for multiphase transport pipelines. In 4th World Conference on Experimental Heat Transfer, Fluid Mechanics and Thermodynamics, pp. 1045-1052; 1997.

[23] Bevilacqua M, Giacchetta G, Neilson KL. Two-phase liquid-gas separation with a new conception comb separator. In 7th International Conference on Multiphase Flow in Industrial Plants, Bologna, pp. 13-15; 2000.

[24] Wren E. Geometric effects on phase split at a large diameter T-junction. Ph.D. Thesis, University of Nottingham, Nottingham, UK; 2001.

[25] Baker G. Separation and control of gas-liquid flows at horizontal T-junctions. Ph.D. Thesis, University of Nottingham, UK; 2003.

[26] Yang L, Zhao Z, Qi P, Zhao L, Azzopardi BJ. Phase separation of gas-liquid twophase flows in multitube $\mathrm{T}$-junction separators. In $2^{\text {nd }}$ China Energy Scientist Forum, pp. 2285-2292; 2010.

[27] Wren E, Azzopardi BJ. The Phase separation capabilities of two T-junctions placed in series. Chemical Engineering Research and Design 2004;82:364-371.

[28] Pao W, Sam B, Saieed A, Tran CM. Numerical investigation of liquid carryover in T-Junction with different diameter ratios. In IOP Conference Series: Materials Science and Engineering; 2018.

[29] Yang L, Liu S, Li H, Zhang J, Wu Y, Xu J. Gas-liquid flow splitting in T-junction with inclined lateral arm. Journal of Hydrodynamics 2018;30173-176.

[30] Liu Y, Li WZ. Numerical simulation on two-phase bubbly flow split in a branching T-junction. International Journal of Air-Conditioning and Refrigeration 2011;19:253-262.

[31] Elguerri M. Experimental study of separation of two-phase flow gas-liquid. Journal of Materials and Enviornmental Sciences 2018;9:1787-1795.

[32] Taitel Y, Dukler AE. A model for predicting flow regime transitions in horizontal and near horizontal gas-liquid flow. AICHE Journal 1976;22:47-55. 